\title{
Inter-hemispheric imaging of the ionosphere with the upgraded IRI-Plas model during the space weather storms
}

\author{
T. L. Gulyaeva ${ }^{1,2}$, F. Arikan $^{3}$, and I. Stanislawska ${ }^{2}$ \\ ${ }^{1}$ IZMIRAN, 142190 Troitsk, Moscow Region, Russia \\ ${ }^{2}$ Space Research Center, PAS, Warsaw, Poland \\ ${ }^{3}$ Department of EEE, Hacettepe University, Beytepe, Ankara 06800, Turkey
}

(Received November 24, 2010; Revised April 25, 2011; Accepted April 25, 2011; Online published December 29, 2011)

\begin{abstract}
International Reference Ionosphere extended to the plasmasphere (IRI-Plas) is upgraded analytically for assimilative mode of operation using GPS-derived Total Electron Content (TEC) for reconstruction of instantaneous ionospheric critical frequency and topside scale height at magnetic conjugate hemisphere. The performance of IRI-Plas code is examined with $\mathrm{TEC}_{\mathrm{gps}}$ retrieved from Global Ionospheric Maps compared with the $F_{2}$-layer critical frequency at eight ionosonde locations in East Asia region on both hemispheres during the space weather storms at solar maximum (2000) and solar minimum (2006). Missing ionosonde data are completed by cloning of critical frequency. Decomposition of $\mathrm{TEC}_{\mathrm{gps}}$ in electron density profile with IRI-Plas code reveals the opposite relative changes of critical frequency and the topside scale height depending on solar activity. The ionospheric weather $W$ index is computed for the desired locations in conjugate hemispheres and consistent results are obtained indicating the departure of instantaneous values of ionospheric parameters from their respective median varying from quiet state to intense storm.
\end{abstract}

Key words: Ionosphere, plasmasphere, GPS, Total Electron Content, magnetic conjugacy, model, IRI.

\section{Introduction}

The history of investigations into inter-hemispheric conjugate effects in the ionosphere can be traced back to early 1960 s. Though the monthly median values of the $F_{2}$-layer critical frequency at conjugate low-latitude stations showed poor correlations, deviations from the median exhibited positive conjugate correlations in all seasons for both geomagnetically quiet and disturbed days (Matsushita, 1968). In Rotwell (1962), the relations of the noon $F_{2}$-layer critical frequency have been investigated for the magnetic conjugate locations at the ends of the magnetic line of force assuming that the daytime temperature of the neutral gas is proportional to the cosine of the Sun's zenith angle at local noon. The correction factor deduced for this relation, the so-called magnetic " $M$-factor", has been expanded for the diurnal, seasonal, solar cycle and spatial variations, and is used for constructing the empirical model of the $f_{\mathrm{o}} F_{2}$ critical frequency using the data from a global network of ionosondes (Besprozvannaya, 1987, 1991, 1995; Chasovitin et al., 1987). The $M$-based model is used in the present study as a quiet reference for the $F_{2}$-layer critical frequency at magnetic conjugate locations.

Renewed interest in the conjugate effects in the Earth's environment has been raised by the ICESTAR Program which focuses on the "Inter-hemispheric Similarities and Asymmetries in Geospace Phenomena" (http://www.scar.

Copyright (C) The Society of Geomagnetism and Earth, Planetary and Space Sciences (SGEPSS); The Seismological Society of Japan; The Volcanological Society of Japan; The Geodetic Society of Japan; The Japanese Society for Planetary Sciences; TERRAPUB.

doi:10.5047/eps.2011.04.007 icestar.org/). The primary goal of the ICESTAR Program is to create an integrated, quantitative description of the upper atmosphere over Antarctica, and its coupling to the global atmosphere and the geospace environment. It is found that there exists a systematic displacement for the sub-storm onset locations in one hemisphere compared to the other (Ostgaard et al., 2007). At the same time, no evidence of geomagnetic conjugacy in pulsating aurora is found, as discussed in Watanabe et al. (2007). The authors report two types of non-conjugacy: (i) pulsating auroras can appear in both hemispheres but their spatial appearance and period are different and (ii) pulsating auroras appear only in one hemisphere.

Recent studies of conjugate effects are not restricted to auroral phenomena. The existence of a global asymmetry in the neutral upper-atmospheric density between the Northern and Southern hemispheres has been indicated (Illes-Almar and Almar, 2006). The authors assume that the phenomenon can be related to the asymmetric distribution of the continents and oceans between the hemispheres and/or with the asymmetry of the geographic field to the geomagnetic field. At the same time, the special campaign of mid-latitude airglow observations at the conjugate locations in Japan and Australia has revealed a one-to-one correspondence of wave structures between the Northern and Southern hemispheres, indicating strong electro-dynamic coupling between the two hemispheres through the geomagnetic field line (Shiokawa et al., 2005).

The simultaneous observations of the $F_{3}$-layer at the lowlatitudinal meridional network located in Southern Asia confirmed the plasma-diffusion effects along the magnetic 
field lines in the low-latitude region (Uemoto et al., 2007). A more sophisticated picture of the ionospheric $E$ - and $F_{2}$-region parameters has been obtained in special nearequatorial empirical conjugate studies in Brazil (McNamara et al., 2008; MacDougall et al., 2009). Considerations of the ambient conditions at the conjugate locations indicate that relatively small differences in parameters such as tidal winds, electric fields, and background density gradients can significantly affect the structuring of the $E_{\mathrm{s}}$ layer. Variations of the $F_{2}$-layer peak density and height appear to result from a reshaping of the $F_{2}$-layer manifested by the scale height around the peak.

The ionospheric behavior in conjugate hemispheres during an annular solar eclipse has clearly indicated that due to the eclipse, fewer photoelectrons travel along the magnetic field lines from the eclipse region to the conjugate region resulting in reduced photoelectron heating in the conjugate hemisphere causing a drop in the electron temperature and a subsequent positive disturbance effect in the peak electron density, peak height and Total Electron Content (Le et al., 2009).

One of the most acknowledged models of the ionosphere suitable for investigations of conjugate phenomena is the International Reference Ionosphere (IRI) (Rawer, 1988, 1990; Bilitza et al., 1993; Bilitza, 2001). The IRI model has been traditionally based on observations of monthly medians of ionospheric parameters obtained from ionosondes mostly located in the northern hemisphere. The temporal and spatial sparsity of data that has been included in the development of the IRI model can be compensated for either by assimilation of new ionosonde results, or by upgrading the IRI model to include situations like space weather storms. When the first option is not feasible, it is better to approach the problem with a cost-effective improvement in the IRI model. The International Reference Ionosphere extended to the plasmasphere (IRI-Plas) (Gulyaeva et al., 2002) is a recent version of IRI where the region of interest can include the plasmasphere up to a height of 20,200 $\mathrm{km}$. The Global Positioning System (GPS) derived Total Electron Content (TEC) can be incorporated into IRIPlas for a better representation of temporal variations in the ionosphere, and the interaction between magnetic conjugate hemispheres can be used to model the ionosphere in regions where ionosonde data are not available.

In the International Reference Ionosphere (IRI) model, the topside and bottomside electron density descriptions use a 'relative layer shape' formula depending on vertical coordinate adapting the absolute values to those at the peak (Rawer, 1988, 1990; Bilitza et al., 1993). Since plasma interchange in the $F$-region is field aligned, it is not possible to describe adequately the spatial structures occurring at low latitudes when admitting that they depend exclusively on the vertical coordinate as is supposed in IRI (Rawer, 1990). The reference peak electron density and height in the IRI system are provided by the ITU-R (former CCIR) or URSI maps. For the conjugate $F_{2}$ peak reconstruction, the IRI driven quiet reference-critical-frequency is replaced in the present study by an $M$-based empirical ionospheric model (Besprozvannaya, 1987, 1991, 1995) which accounts for the magnetic field geometry. Since the IRI $F_{2}$-layer peak-height yields inadequate results in some regions of the Southern hemisphere, the model peak height $h_{\mathrm{m}} F_{2}$ is improved (Chasovitin et al., 1987) as derived from the ITU$\mathrm{R}$ (former CCIR) maps of $M_{3000} F_{2}$ using the formulations of Bilitza et al. (1979) for the Northern hemisphere and supposed to be symmetric in the Southern hemisphere.

The term 'Imaging of the ionosphere' is well-recognized in the tomographic decomposition of the GPS-derived Total Electron Content $\left(\mathrm{TEC}_{\mathrm{gps}}\right)$ into the electron density distribution (Bust and Mitchell, 2008). In their review, an introduction and the history of ionospheric imaging is presented, beginning with computerized ionospheric tomography. The ability of imaging algorithms to incorporate multiple types of data and use advanced inverse techniques borrowed from meteorological data assimilation to produce four-dimensional images of electron density is discussed therein. The technique implemented in the present paper is based on a sort of data assimilation scheme of $\mathrm{TEC}_{\mathrm{gps}}$ values obtained using the Global Ionospheric Maps (GIM) (Manucci et al., 1998; Nayir et al., 2007). While TEC measurements at GPS-receivers sites are more accurate compared with spatially- and temporally-smoothed GIM TEC products, the GIM data are readily available for extracting (interpolation) the TEC value at any given location, in particular, in the conjugate hemisphere.

The International Reference Ionosphere model extended to GPS heights in the plasmasphere, IRI-Plas, (Gulyaeva et al., 2002) is used for retrieving the electron density height profile from $\mathrm{TEC}_{\mathrm{gps}}$ input (Gulyaeva, 2011). Guided by the knowledge gained from previous data analysis, the IRI-Plas algorithm is complemented with a feedback loop in order to update two model parameters: (1) an instantaneous peak electron density that is proportional to the square of the $F_{2}$ layer critical frequency, and (2) the electron density scale height at the lower topside.

In this study, the instantaneous ionospheric critical frequency will be reconstructed using a new technique for conjugate hemispheres. The validation will be achieved by a comparison of reconstructed critical frequency values with the ionosonde source station (SS) data. The proposed data assimilation technique makes use of the TEC maps provided by GIM for the estimate of $\mathrm{TEC}_{\mathrm{gps}}$. The $\mathrm{TEC}_{\mathrm{gps}}$ data representing an integral of plasma density characteristics in the Earth's environment, which embraces the plasma transfer between the hemispheres along the magnetic lines of force, are the most suitable for magnetic conjugacy studies by providing an independent source of information at the conjugate points, $\mathrm{CP}$. $\mathrm{TEC}_{\mathrm{gps}}$ provides an estimate of the total number of free electrons inside the cylinder with $1-\mathrm{m}^{2}$ cross-section area in the column from the bottom of the ionosphere $(65 \mathrm{~km})$ to $20,200 \mathrm{~km}$ (GPS orbit). The $\mathrm{TEC}_{\mathrm{gps}}$ also exhibits the temporal variability of the ionosphere and the plasmasphere. Therefore, the assimilation of $\mathrm{TEC}_{\mathrm{gps}}$ into the IRI-Plas code provides a more accurate representation of critical ionospheric parameters especially at $\mathrm{CP}$ points, both under quiet, and under storm, conditions. In Section 2, the new technique of the assimilation of $\mathrm{TEC}_{\mathrm{gps}}$ data into IRI-Plas is discussed. Section 3 includes the validation of the modified IRI-Plas during storm conditions. 


\section{Data Processing}

The data used for the present study are obtained from various sources. The ionosonde-derived $F_{2}$-layer critical frequency, $f_{\mathrm{o}} F_{2}$, and the height, $h_{\mathrm{m}} F_{2}$, are provided by global and national Data Centers on the World Wide Web. The ionosonde locations of the source stations, SS, in a geographic frame, their corrected magnetic coordinates and the geographic coordinates of their magnetic conjugate points, $\mathrm{CP}$, are given in Table 1 . The region of interest spans from $-60^{\circ} \mathrm{N}$ to $60^{\circ} \mathrm{N}$ of magnetic latitude and from $120^{\circ} \mathrm{E}$ to $170^{\circ} \mathrm{E}$ of geographic longitude. Figure 1 shows a map of station locations, indicated by cycles, related by a dashed line to their magnetic conjugate counterpoints, that are denoted by diamonds. Using the IGRF-2000 magnetic field model, the magnetic field line was traced from a $300-\mathrm{km}$ altitude at the source location to a $300-\mathrm{km}$ altitude at the conjugate hemisphere.

The gaps in SS ionosonde observations are filled up using the cloning procedure discussed in Gulyaeva et al. (2008). The variations in $f_{\mathrm{o}} F_{2}$ at a 'parent' station are used for the reconstruction of a measurement missed at another location. The transform is applied to the proxy for the $F_{2}$-layer critical frequency reduced by the solar zenith angle which improves the correlation between the data at different locations (Gulyaeva, 2009). This procedure assumes the availability of the daily-hourly values of critical frequency measured at a particular parent station and the median for the preceding 27 days at both stations.

The electron-density profile and the $F_{2}$-layer critical frequency at the conjugate locations are obtained using the 3-D ionosphere-plasmasphere model, IRI-Plas. The IRIPlas code provides a three-dimensional and time-dependent global model of electron-density, $N_{\mathrm{e}}(h)$, and temperature, $T_{\mathrm{e}}(h)$, profiles through the ionosphere and plasmasphere. The $N_{\mathrm{e}}(h)$ profile is fitted to anchor points at the $F_{2}$-layer peak electron density, $N_{\mathrm{e}} F_{2}$, and height, $h_{\mathrm{m}} F_{2}$, which can be modeled using ITU-R (former CCIR) maps of $f_{\mathrm{o}} F_{2}$ and $M_{3000} F_{2}$, or they can be derived experimentally. The model predicts the Total Electron Content, $\mathrm{TEC}_{\mathrm{iri}}$, by numerical integration of the $N_{\mathrm{e}}(h)$ profile from an altitude of $65 \mathrm{~km}$ to a few Earth's radii (specified currently at 20,000 km near the GPS orbit) for the desired location, date and time.

The IRI-Plas code is updated for the assimilation of the $\mathrm{TEC}_{\mathrm{gps}}$ as discussed in Gulyaeva (2011). The $\mathrm{TEC}_{\mathrm{gps}}$ data for SS and CP sites are extracted from the GIM maps produced by the Jet Propulsion Laboratory, provided online at ftp://cddis.gsfc.nasa.gov/pub/gps/ products/ionex/. The GIMs provided with a temporal resolution of 2 hours are linearly interpolated for a 1 -h resolution. In the literature, there are various techniques providing the assimilation of $\mathrm{TEC}_{\mathrm{gps}}$ data by an updated IRI code, or other profilers (Komjathy et al., 1998; Stankov et al., 2003; Yizengaw et al., 2006). In our approach, the topside IRI electrondensity profile is linked with the plasmasphere model, IRIPlas, (Gulyaeva et al., 2002) at an altitude of one basisscale-height above the $F_{2}$ peak (Gulyaeva, 2011) close to the $\mathrm{O}^{+} / \mathrm{H}^{+}$transition height, where the concentration of hydrogen becomes comparable with that of oxygen. The topside basis-scale-height, $H_{\mathrm{sc}}$, presents the distance in $\mathrm{km}$ above the peak height at which the peak plasma density,

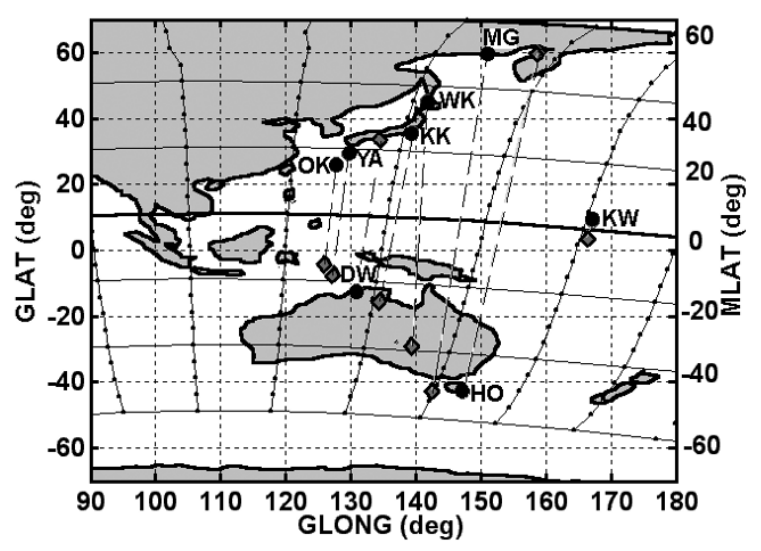

Fig. 1. Stations used for ionospheric data processing denoted by circles and their magnetic conjugate counterparts denoted by diamonds.

$N_{\mathrm{e}} F_{2}$, decays by a factor of $e(\sim 2.718)$.

The peak plasma density, in $\mathrm{m}^{-3}$, is related to the critical frequency, in $\mathrm{Hz}$, by the expression:

$$
N_{\mathrm{e}} F_{2}=\left(f_{\mathrm{o}} F_{2}\right)^{2} / 80.6
$$

In the present study, the algorithm applied in the IRI-Plas model for obtaining the topside scale height, $H_{\mathrm{sc}}$, when the $F_{2}$-peak parameters are available from observation (Gulyaeva, 2011) is updated using the input of GPS-derived TEC to obtain both the instantaneous peak electron density and the topside scale height by fitting the model result $\mathrm{TEC}_{\text {iri }}$ to $\mathrm{TEC}_{\mathrm{gps}}$.

The first run of the IRI-Plas code does not require the input of the $F_{2}$-layer peak parameters since it is based on the median ( $M$-model) critical frequency $f_{\mathrm{m}} F_{2}$ and the IRI-CCIR peak height $h_{\mathrm{m}} F_{2}$ providing the model output of $\mathrm{TEC}_{\mathrm{iri}}{ }^{0}$. Then, using the $\mathrm{TEC}_{\mathrm{gps}}$ input with the IRI-Plas code, we attribute the difference between the model and the measured TEC at altitudes from $65 \mathrm{~km}$ to $20,200 \mathrm{~km}$ (GPS orbit) as a source to update the $F_{2}$-layer peak density for the GPS signal's travel through the oxygen-dominated plasma of the ionosphere and the tenuous hydrogen-dominated plasma of the plasmasphere. Accordingly, we are using the following formula to transform the background reference critical frequency, $f_{\mathrm{m}} F_{2}$, to an instantaneous value $f_{\mathrm{o}} F_{2}$ $\left(N_{\mathrm{e}} F_{2}\right)$ according to the $\mathrm{TEC}_{\mathrm{gps}}$ input at $\mathrm{CP}$ as:

$$
N_{\mathrm{e}} F_{2}=N_{\mathrm{m}} F_{2} \times \mathrm{TEC}_{\mathrm{gps}} / \mathrm{TEC}_{\mathrm{iri}}{ }^{0}
$$

where $N_{\mathrm{e}} F_{2}$ is the instantaneous peak electron density; $N_{\mathrm{m}} F_{2}$ is the $M$-based model of the quiet reference peak electron density; and $\mathrm{TEC}_{\mathrm{iri}}{ }^{0}$ (with superscript ' 0 ' ) is the pre-fit IRI-Plas Total Electron Content obtained using $f_{\mathrm{m}} F_{2}$ and $h_{\mathrm{m}} F_{2}$ peak parameters. All the above mentioned parameters refer to a specified location at $\mathrm{CP}$.

The IRI-Plas code is further modified using the upgraded $N_{\mathrm{e}} F_{2}$ in Eq. (2) for the re-calculation of the peak height, $h_{\mathrm{m}} F_{2}$, depending on $f_{\mathrm{o}} F_{2}$. Then, we obtain the electrondensity profile, the bottomside electron content, $\mathrm{TEC}_{\mathrm{b}}{ }^{1}$, and the total electron content, $\mathrm{TEC}_{\mathrm{iri}}{ }^{1}$, for recalculating the topside scale height with Eq. (3) (Gulyaeva, 2011):

$$
H_{\mathrm{osc}}=H_{\mathrm{msc}}{ }^{1} \times\left(\mathrm{TEC}_{\mathrm{gps}}-\mathrm{TEC}_{\mathrm{b}}{ }^{1}\right) /\left(\mathrm{TEC}_{\mathrm{iri}}{ }^{1}-\mathrm{TEC}_{\mathrm{b}}{ }^{1}\right)
$$


Table 1. Geographic, and corrected geomagnetic, coordinates of the source ionosonde stations (SS) and geographic coordinates of the magnetic conjugate points $(\mathrm{CP})$ used for the analysis.

\begin{tabular}{|l|c|c|c|r|r|r|}
\hline \multirow{2}{*}{ Station } & \multicolumn{2}{|c|}{ Geographic } & \multicolumn{2}{c|}{ Geomagnetic } & \multicolumn{2}{c|}{ CP } \\
\cline { 2 - 7 } & Glat & Glon & Mlat & Mlon & Glat & Glon \\
\hline Magadan (MG) & 60.0 & 151.0 & 54.5 & 218.6 & -41.8 & 141.3 \\
Wakkanai (WK) & 45.4 & 141.7 & 40.0 & 212.6 & -27.6 & 138.5 \\
Kokubunji (KK) & 35.7 & 139.5 & 30.7 & 210.6 & -18.5 & 137.7 \\
Yamagawa (YA) & 29.2 & 129.6 & 25.0 & 201.1 & -12.3 & 129.2 \\
Okinawa (OK) & 26.3 & 127.8 & 22.4 & 199.2 & -9.5 & 127.6 \\
Kwajalein (KW) & 9.0 & 167.2 & 12.7 & 237.6 & 2.1 & 166.2 \\
Darwin (DW) & -12.2 & 130.9 & -24.9 & 202.8 & 29.2 & 131.4 \\
Hobart (HO) & -42.9 & 147.2 & -55.1 & 226.3 & 60.4 & 161.0 \\
\hline
\end{tabular}

where $H_{\text {osc }}$ denotes the instantaneous topside scale height at the conjugate point; $H_{\mathrm{msc}}{ }^{1}$ is the topside scale height inferred by IRI-Plas execution yielding $\mathrm{TEC}_{\mathrm{iri}}{ }^{1}$ and $\mathrm{TEC}_{\mathrm{b}}{ }^{1}$ output denoted with superscript ' 1 ' obtained with updated $N_{\mathrm{e}} F_{2}$ (Eq. (2)) input. The uncoupling of TEC from the bottomside underlying ionization is accomplished using a residual of $\left(\mathrm{TEC}_{\mathrm{iri}}{ }^{1}-\mathrm{TEC}_{\mathrm{b}}{ }^{1}\right)$ representing the vertical integrated electron content above $h_{\mathrm{m}} F_{2}$ through the topside ionosphere and plasmasphere. The feedback loop is incorporated into the IRI-Plas code for producing the post-fit topside electron-density profile and $\mathrm{TEC}_{\text {iri }}$ using the upgraded $N_{\mathrm{e}} F_{2}$ and $H_{\mathrm{osc}}$. This re-calculation of the IRI-Plas topside, and plasmasphere, electron density is performed by changing the $q$-factor introduced in the topside model (Gulyaeva and Titheridge, 2006) according to the result of Eq. (3).

The relative variations in $N_{\mathrm{e}} F_{2}, f_{\mathrm{o}} F_{2}$, and $H_{\mathrm{osc}}$ are defined as:

$$
\begin{aligned}
r N_{\mathrm{e}} F_{2} & =\log \left(N_{\mathrm{e}} F_{2} / N_{\mathrm{m}} F_{2}\right) \\
r H_{\mathrm{osc}} & =\log \left(H_{\mathrm{osc}} / H_{\mathrm{msc}}\right) \\
r f_{\mathrm{o}} F_{2} & =\log \left(f_{\mathrm{o}} F_{2} / f_{\mathrm{m}} F_{2}\right)
\end{aligned}
$$

where the symbols ' $\mathrm{e}$ ' and 'o' denote the instantaneous value, and ' $m$ ' denotes the quiet reference median or model value. If the logarithm yields a negative value, this is an indicator of a decrease of a parameter value compared to the quiet reference value (negative storm effect). Similarly, a positive value of the logarithms in Eq. (4) above indicates an increase in the value of the parameter of interest (positive storm effect).

In Gulyaeva et al. (2008), a segmented logarithmic scale of the ionospheric weather $W$ index is introduced for the different thresholds of change in $N_{\mathrm{e}} F_{2}$ according to Eq. (4) for quantifying the ionosphere variability. The thresholds of the logarithmic ratios for $N_{\mathrm{e}} F_{2}$ and TEC are selected by equal increments in absolute values for the positive and negative logarithm magnitude which correspond, however, to unequal linear deviations of the particular parameter from the median. As discussed in detail in Gulyaeva et al. (2008), $W= \pm 1$ corresponding to less than about $\pm 10 \%$ changes of $\mathrm{N}_{\mathrm{e}} \mathrm{F}_{2}$ regarding the median represents the quiet ionosphere state, $W= \pm 2\left(-10 \%>W^{-}>-30 \% ; 10 \%<W^{+}\right.$ $<43 \%$ ) denotes a moderate disturbance. When $W= \pm 3$ $\left(-30 \%>W^{-}>-50 \% ; 43 \%<W^{+}<100 \%\right)$, a moderate ionospheric storm is imminent, and finally, $W= \pm 4\left(W^{-}\right.$ $\left.<-50 \% ; W^{+}>100 \%\right)$ is the indicator of an intense iono- spheric storm. Note that thresholds for $r N_{\mathrm{e}} F_{2}$ correspond to the relevant changes of $r f_{\mathrm{o}} F_{2}$ which are two times less, which follows from Eq. (1) and Eq. (4):

$$
r f_{\mathrm{o}} F_{2}=r N_{\mathrm{e}} F_{2} / 2
$$

The results obtained with the above analysis are presented in the next section.

\section{Results}

The current investigation for the magnetic conjugate points is carried out using the eight ionosonde source stations of Table 1. The ionospheric parameters obtained with the above technique at the conjugate hemisphere are compared with SS data obtained from ionosondes at the same hemisphere. The TEC values are obtained from the GIM. The space weather storms that are highly effective in the ionosphere and plasmasphere can be identified and graded using the planetary ionosphere-plasmasphere storm index, $W_{\mathrm{p}}$ (Gulyaeva and Stanislawska, 2008, 2010). The $W_{\mathrm{p}}$ index is derived using the GIM-TEC maps, and they are provided online from 1999 up to the present at http://www.izmiran.ru/services/iweather/.

We have chosen for the analysis the twenty-one ionosphere-plasmasphere storms which occurred during the solar maximum year of 2000 and eight storms which occurred during the year 2006 corresponding to the solar minimum (Table 2). The maximum duration of each storm in hours (h); the peak $W_{\mathrm{p}}$ index reached during the storm; and the peak values of relevant geomagnetic indices: the planetary $A_{\mathrm{p}}$ index (and its integrated equivalent $A_{\mathrm{pi}}$ for the preceding $39 \mathrm{hrs}$ used by the IRI-Storm option), the Auroral Electrojet $A E$ index and the disturbance storm time $D_{\text {st }}$ index are provided in Table 2. The characteristics of the space weather storms that are given in Table 2 indicate that the ionosphere and plasmasphere can be stormy while the magnetosphere remains quiet (Gulyaeva and Stanislawska, 2010).

The Root-Mean-Square (RMS) deviation, in MHz, between the disturbed and quiet $F$-region critical frequency averaged over a number of sites (SS or $\mathrm{CP}$ ) particularly for the Southern (S) and Northern (N) hemispheres (Table 2) demonstrates a measure of disturbance of the peak electron density which is consistent for the observed $f_{\mathrm{o}} F_{2}$ (SS) and the reconstructed critical frequency $(\mathrm{CP})$ with the proposed algorithm. 
Table 2. Planetary ionosphere-plasmasphere storms deduced from IGS-TEC maps during solar maximum (2000) and solar minimum (2006) and extreme space weather indices used in the present study at the conjugate hemispheres. Root-mean-square RMS deviation, in MHz, between the disturbed and quiet $F$-region critical frequency is averaged over a number of sites (SS or CP) in the Southern (S) or Northern (N) hemispheres.

\begin{tabular}{|c|c|c|c|c|c|c|c|c|c|}
\hline $\mathrm{Nn}$ & $\begin{array}{l}\text { Storm onset } \\
\text { date_UT, h }\end{array}$ & $\begin{array}{l}\text { Storm end } \\
\text { date_UT, h }\end{array}$ & $\begin{array}{l}\text { Duration, } \\
\Sigma \mathrm{h}\end{array}$ & $\begin{array}{c}W_{\mathrm{p}} \\
\max \end{array}$ & $\begin{array}{l}A_{\mathrm{p}-} A_{\mathrm{pi}} \\
\max , \mathrm{nT}\end{array}$ & $\begin{array}{c}A E \\
\max \end{array}$ & $\begin{array}{l}D_{\text {st }} \\
\min \end{array}$ & $\begin{array}{c}\text { RMS at S } \\
\text { SS_CP }\end{array}$ & $\begin{array}{c}\text { RMS at N } \\
\text { SS_CP }\end{array}$ \\
\hline \multicolumn{10}{|c|}{ Solar maximum, 2000} \\
\hline 1 & Jan 11_18 & Jan 12_12 & 19 & 6.6 & $56 \_376$ & 1124 & -81 & 2.31_1.35 & 2.59_0.92 \\
\hline 2 & Jan 29_16 & Jan 30_08 & 17 & 6.1 & $39 \_524$ & 745 & -33 & $1.12 \_1.43$ & $1.15 \_0.67$ \\
\hline 3 & Feb 11_20 & Feb 13_18 & 47 & 6.8 & 111_1088 & 1124 & -133 & $1.93 \_1.06$ & 2.18_1.75 \\
\hline 4 & Apr 06_18 & Apr 08_08 & 39 & 9.5 & $300 \_2511$ & 1550 & -288 & $3.47 \_1.60$ & 2.07_1.33 \\
\hline 5 & May 02_12 & May 05_16 & 77 & 6.6 & 39_384 & 901 & -37 & $1.89 \_1.76$ & $1.80 \_1.36$ \\
\hline 6 & May 07_04 & May 08_04 & 25 & 6.5 & 7_164 & 509 & -10 & $1.06 \_1.74$ & $1.57 \_1.29$ \\
\hline 7 & May 24_00 & May $25 \_10$ & 35 & 6.4 & 207_1701 & 1336 & -147 & 2.60_1.10 & $2.09 \_1.22$ \\
\hline 8 & May 30_16 & June 01_04 & 37 & 6.0 & $32 \_532$ & 827 & -54 & 2.88_1.18 & $1.30 \_0.96$ \\
\hline 9 & June 08_16 & June 09_00 & 9 & 6.5 & $132 \_1137$ & 1334 & -90 & $1.34 \_0.47$ & $2.34 \_1.79$ \\
\hline 10 & July 14_18 & July 17_09 & 64 & 10.2 & 400_3442 & 1657 & -301 & $2.65 \_1.06$ & $2.03 \_1.53$ \\
\hline 11 & July 23_15 & July 24_03 & 13 & 6.1 & $80 \_373$ & 1008 & -68 & $0.82 \_1.57$ & $0.71 \_0.66$ \\
\hline 12 & July 28_15 & July 29_00 & 10 & 6.1 & $67 \_620$ & 1166 & -51 & $0.85 \_0.76$ & 1.71_1.40 \\
\hline 13 & Aug 09_22 & Aug 13_00 & 75 & 8.2 & 179_2144 & 1107 & -235 & $2.16 \_1.02$ & $1.86 \_1.22$ \\
\hline 14 & Sep 16_22 & Sep 19_00 & 51 & 9.4 & 236_1670 & 1009 & -201 & $2.92 \_0.93$ & 1.28_0.64 \\
\hline 15 & Sep 30_08 & Oct $01 \_00$ & 17 & 6.3 & $94 \_865$ & 1290 & -76 & 2.17_1.58 & $1.28 \_1.28$ \\
\hline 16 & Oct $02 \_08$ & Oct $05 \_14$ & 79 & 8.4 & $154 \_2215$ & 1457 & -182 & $3.71 \_1.18$ & 1.91_1.57 \\
\hline 17 & Oct 14_06 & Oct $15 \_00$ & 19 & 6.9 & 111_777 & 1133 & -107 & 1.87_0.94 & $1.25 \_1.01$ \\
\hline 18 & Oct $22 \_20$ & Oct 23_00 & 5 & 6.3 & 39_358 & 913 & -41 & $0.98 \_0.58$ & $0.87 \_0.51$ \\
\hline 19 & Nov 04_10 & Nov 04_13 & 4 & 7.0 & 48_427 & 791 & -50 & $1.37 \_0.82$ & 1.06_0.84 \\
\hline 20 & Nov 06_13 & Nov 07_10 & 22 & 7.4 & $132 \_843$ & 1154 & -159 & $2.13 \_3.09$ & $1.79 \_1.82$ \\
\hline 21 & Nov 27_12 & Nov 29_10 & 47 & 6.9 & 94_1016 & 1210 & -119 & $1.72 \_0.82$ & $1.76 \_1.44$ \\
\hline \multicolumn{10}{|c|}{ Solar minimum, 2006} \\
\hline 22 & Mar 18_10 & Mar 19_03 & 18 & 6.0 & $94 \_892$ & 850 & -40 & $0.71 \_0.49$ & $0.74 \_0.37$ \\
\hline 23 & Apr 05_01 & Apr 06_13 & 37 & 6.5 & $56 \_522$ & 959 & -87 & $1.34 \_0.84$ & 1.71_1.02 \\
\hline 24 & Apr 09_04 & Apr 09_23 & 20 & 6.0 & $80 \_726$ & 726 & -80 & 0.98_0.92 & $1.44 \_1.00$ \\
\hline 25 & Apr 13_23 & Apr 16_08 & 58 & 7.9 & 132_1151 & 1437 & -111 & $1.61 \_1.30$ & 1.80_1.15 \\
\hline 26 & May 04_12 & May 05_13 & 26 & 6.5 & 39_292 & 1012 & -42 & $0.91 \_0.56$ & $1.23 \_0.73$ \\
\hline 27 & Aug 19_15 & Aug 21_01 & 35 & 6.5 & 80_942 & 1637 & -71 & $0.92 \_0.68$ & $0.84 \_0.44$ \\
\hline 28 & Nov 09_19 & Nov 12_13 & 57 & 7.0 & $80 \_703$ & 1042 & -51 & 0.98_1.04 & 1.00_0.75 \\
\hline 29 & Dec 14_17 & Dec 16_17 & 49 & 10.9 & 236_2135 & 1616 & -146 & $1.80 \_0.89$ & 1.81_0.85 \\
\hline
\end{tabular}

Table 3. RMS deviation of $\mathrm{TEC}_{\text {iri }}$ from $\mathrm{TEC}_{\mathrm{gps}}$, in TECU, at the main phase of the ionospheric storms at solar maximum (2000) and solar minimum (2006). Results of IRI-Plas model for two options: (1) ionosonde-derived input of $f_{\mathrm{o}} F_{2}$ and $h_{\mathrm{m}} F_{2}$ combined with input of TEC $\mathrm{gps}$, (2) input of $f_{\mathrm{o}} F_{2}$ and $h_{\mathrm{m}} F_{2}$ from ionosonde alone. Instantaneous results (i) and monthly median results (m) are shown. Data are missing for two stations for 2000

\begin{tabular}{|c|c|c|c|c|c|c|c|c|}
\hline \multirow[t]{2}{*}{ Station } & \multicolumn{4}{|c|}{2000} & \multicolumn{4}{|c|}{2006} \\
\hline & RMS(1)i & RMS(2)i & $\mathrm{RMS}(1) \mathrm{m}$ & $\mathrm{RMS}(2) \mathrm{m}$ & RMS(1)i & $\operatorname{RMS}(2) \mathrm{i}$ & RMS(1)m & RMS(2)m \\
\hline Magadan & 0.68 & 2.54 & 0.34 & 1.32 & 0.13 & 1.16 & 0.10 & 0.76 \\
\hline Wakkanai & 1.26 & 2.57 & 0.50 & 1.96 & 0.19 & 1.12 & 0.18 & 1.36 \\
\hline Kokubunji & 0.80 & 2.38 & 0.22 & 1.10 & 0.24 & 1.43 & 0.17 & 1.41 \\
\hline Yamagawa & - & - & - & - & 0.70 & 2.60 & 0.29 & 2.07 \\
\hline Okinawa & 1.92 & 5.31 & 0.37 & 1.83 & 0.25 & 2.40 & 0.18 & 1.48 \\
\hline Kwajalein & - & - & - & - & 0.75 & 3.86 & 0.53 & 2.74 \\
\hline Darwin & 1.51 & 3.87 & 1.42 & 2.44 & 0.42 & 3.75 & 0.13 & 0.97 \\
\hline Hobart & 0.48 & 1.56 & 0.17 & 0.79 & 0.36 & 0.97 & 0.03 & 0.28 \\
\hline
\end{tabular}

The IRI-Plas code is validated as the 3-D interpolator of $\mathrm{TEC}$, at the source stations. The $\mathrm{TEC}_{\text {iri }}$ calculation, with instantaneous and median $\mathrm{TEC}_{\mathrm{gps}}$ incorporation, is compared in Table 3 using two IRI-Plas options. In the first option, the post-fit $\mathrm{TEC}_{\text {iri }}$ is obtained from Eq. (3). In this option, $f_{\mathrm{o}} F_{2}$ is not modified as provided in Eq. (2). Thus, all the difference between model $\mathrm{TEC}_{\text {iri }}$ and $\mathrm{TEC}_{\mathrm{gps}}$ is attributed to the topside scale height. The values of $f_{\mathrm{o}} F_{2}$ and $h_{\mathrm{m}} F_{2}$ (both instantaneous and the monthly median) are based on the results from the ionosonde observations along with the $\mathrm{TEC}_{\mathrm{gps}}$ input. In the second option, $\mathrm{TEC}_{\mathrm{iri}}$ computations are anchored to the same $f_{\mathrm{o}} F_{2}$ and $h_{\mathrm{m}} F_{2}$ data alone from ionosonde measurements (both instantaneous and the monthly median) without the input of $\mathrm{TEC}_{\mathrm{gps}}$.

The RMS difference between $\mathrm{TEC}_{\mathrm{iri}}$ and $\mathrm{TEC}_{\mathrm{gps}}$, obtained with the data of the source stations, is listed in Table 3 for both the solar maximum and the solar minimum years. It is natural that a low RMS value is obtained with the 


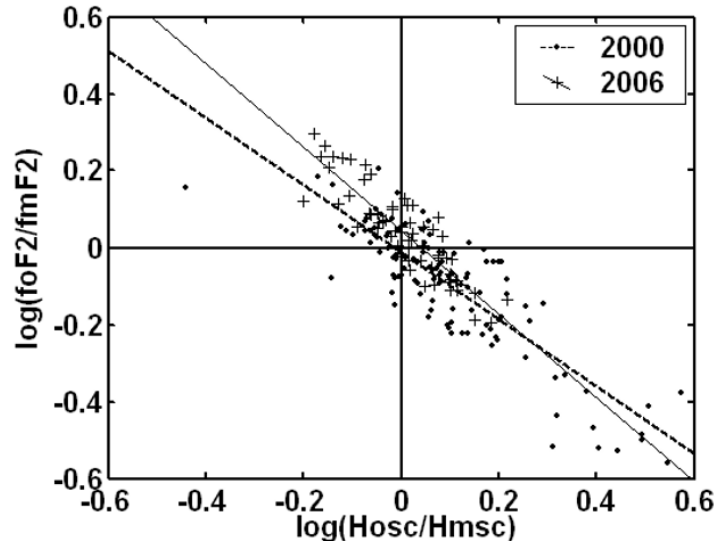

Fig. 2. Opposite relative changes of the $F_{2}$-layer critical frequency versus topside scale height during storms at solar maximum (dots, 2000) and solar minimum (crosses, 2006) and the analytical model (dashed line-2000, thin solid line-2006) in a bi-logarithmic frame.

parameters derived from the $\mathrm{TEC}_{\mathrm{gps}}$ (option 1) because the $\mathrm{TEC}_{\mathrm{gps}}$ values were used for computing these parameters. Differences in the RMS obtained for the instantaneous and median post-fit $\mathrm{TEC}_{\text {iri }}$ are considered in more detail in the 'Discussion and Conclusions' section. Results of reshaping the electron density profile with IRI-Plas code using option 1 and option 2 suggest that incorporation of only the $F_{2}$ layer peak parameters observed with an ionosonde can yield a model $\mathrm{TEC}_{\mathrm{iri}}$ which differs from $\mathrm{TEC}_{\mathrm{gps}}$ data.

The opposite relative variations of the critical frequency, $r f_{\mathrm{o}} F_{2}$, with respect to the topside scale height, $r H_{\mathrm{osc}}$, have been presented in Gulyaeva (2011). In this study, $r f_{\mathrm{o}} F_{2}$ and $r H_{\text {osc }}$ data retrieved with IRI-Plas, adapting the model to $\mathrm{TEC}_{\mathrm{gps}}$ (option 1 of Table 3 ) are provided in Fig. 2 in a bilogarithmic scale both for the solar minimum and the solar maximum. In Fig. 2, the points denote the solar maximum year 2000 data, where the mean smoothed sunspot number $R_{\mathrm{z}}$ is 136 . The solar minimum year 2006 data (where $R_{\mathrm{z}}=13$ ) are indicated with crosses on the same figure. The best-fit regression lines are denoted with the dashed line and the solid thin line for 2000 and 2006, respectively. The correlation coefficients are $r_{2}=-0.85$ for the solar maximum and $r_{2}=-0.88$ for the solar minimum, an indicator of strong anti-correlation of variability of these two ionospheric parameters.

Since solar activity is effective in the relationship between the critical frequency and the topside scale height, $R_{\mathrm{z}}$ is incorporated into the analysis using a linear interpolation between the coefficients of two regression lines for the solar minimum and maximum. Thus, the link between $r f_{\mathrm{o}} F_{2}$ and $r H_{\mathrm{osc}}$ is expressed in the following equation as:

$$
\begin{aligned}
r f_{\mathrm{o}} F_{2}= & -r H_{\mathrm{osc}} \times\left(1.10756-0.001747 \times R_{\mathrm{z}}\right) \\
& +0.05175-0.000472 \times R_{\mathrm{z}}
\end{aligned}
$$

The instantaneous value of $f_{\mathrm{o}} F_{2}$ can be retrieved from Eqs. (4) and (6) using $r f_{\mathrm{o}} F_{2}$ and the median or quiet reference model $f_{\mathrm{m}} F_{2}$ values as:

$$
f_{\mathrm{o}} F_{2}=f_{\mathrm{m}} F_{2} \times 10^{r f_{\mathrm{o}} F_{2}}
$$

The performance of the IRI-Plas code in the derivation of the $F_{2}$-layer critical frequency at magnetic conjugate locations using Eq. (2) and Eq. (3) is examined using the cross-correlation coefficient, $r_{2}$, between the SS data and the $\mathrm{CP}$ instantaneous reconstructed critical frequency. A very high correlation is observed for all the storm conditions presented in Table 2. For example, for the ionosphereplasmasphere storm on 12-13 August, 2000, at the solar maximum, $r_{2}$ is equal to 0.88 for the Northern Hemisphere and 0.63 for the Southern Hemisphere. This is a very strong result that indicates the efficiency and accuracy of the developed reconstruction technique. A visual example is provided in Fig. 3 for this storm.

The ionosonde observations of $f_{\mathrm{o}} F_{2}$ are shown for the source stations in Fig. 3(a), and their conjugate counterparts retrieved with Eqs. (2)-(3) are given in Fig. 3(b). The solid curve denotes the 27-day median $f_{\mathrm{m}} F_{2}$ at SS (a), and the solid line indicates the $M$-based model at CP (b). The corrected magnetic latitudes of SS and $\mathrm{CP}$ (equal in absolute value but opposite in sign in the conjugate hemispheres) are indicated at the right border of each panel. The crosses denote the instantaneous critical frequency, $f_{\mathrm{o}} F_{2}$, which is the ionogram derived values at SS (a) and retrieved from $\mathrm{TEC}_{\mathrm{gps}}$ values for CP (b). The negative phase of the ionospheric storm is evident at the four ionosonde SS where $f_{\mathrm{o}} F_{2}$ values are depleted with respect to the median, excluding the few hours of positive enhancement signatures at Darwin during the first day. Similar dominating effects of the negative storm are obtained at the conjugate locations, where the positive storm signatures at the conjugate magnetic latitude of $-31^{\circ}$ for Kokubunji are very similar to those of Darwin station located at the low magnetic latitude of $-25^{\circ}$ in the winter Southern hemisphere. We remind that all these features are retrieved due to $\mathrm{TEC}_{\mathrm{gps}}$ changes. Thus, the similarity of $\mathrm{CP} f_{\mathrm{o}} F_{2}$ variability to those of SS observations in the relevant hemisphere is very promising.

For another storm on December 15, 2006, at the solar minimum, the correlation coefficients are calculated as $r_{2}=$ 0.98 for the Northern hemisphere, and as 0.94 for the Southern Hemisphere. In Fig. 4, the ionosonde SS data and the reconstructed CP counterparts are provided for the December 15,2006 , storm. The results for SS (a) and CP (b) are presented in succession varying from the negative bottom magnetic latitudes for the Southern hemisphere (indicated at the right border of each panel) towards the positive magnetic latitudes upward for the Northern hemisphere. Here, the positive phase of the storm is captured by both the empirical data (a) and the model retrieved critical frequency at $\mathrm{CP}$ (b). The enhancement of the peak plasma density (or the critical frequency) propagates in the winter Northern hemisphere from high latitudes towards the equator during daytime. This effect is gradually replaced by a negative $f_{\mathrm{o}} F_{2}$ decrease in the Southern summer hemisphere. At the conjugate sites, the peak plasma density shows a similar pattern of enhancement in the winter Northern hemisphere gradually reducing towards the equator and propagating as a negative plasma depletion towards the Southern high latitudes.

The retrieval of the critical frequency at conjugate locations is most advantageous for mapping purposes when the ionosonde network is absent or sparse. Two examples are 


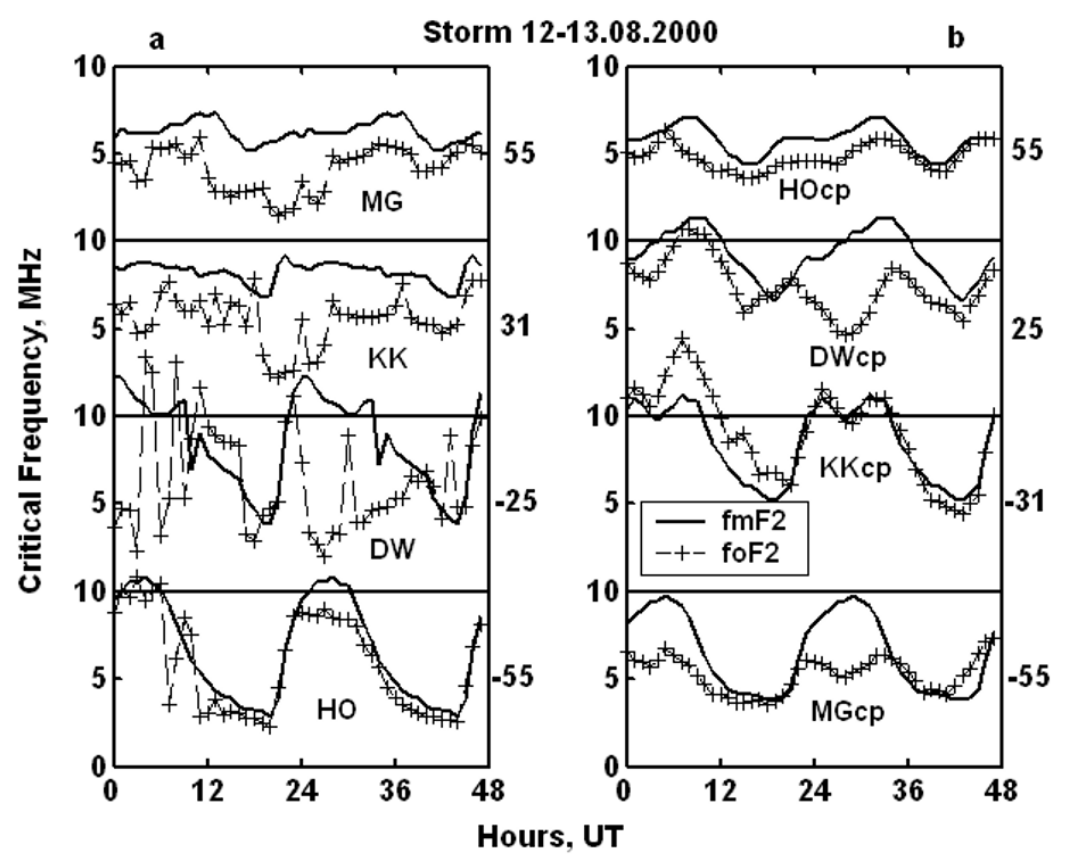

Fig. 3. Observations of the $F_{2}$-layer critical frequency at source stations (left panel) and model reconstruction at the conjugate hemisphere (right panel) during the ionosphere-plasmasphere storm on 12-13 August, 2000, at solar maximum. The solid line indicates the median values, and the dashed line denotes the instant values.

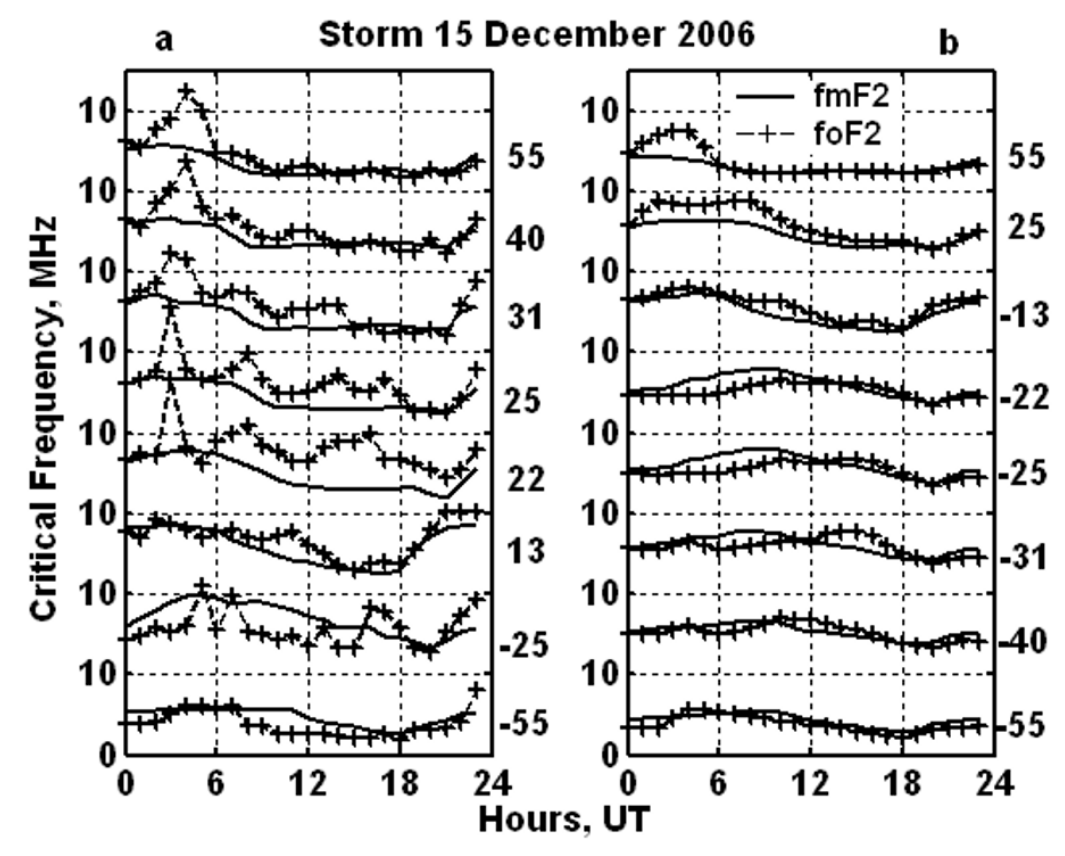

Fig. 4. Observations of the $F_{2}$-layer critical frequency at source stations (left panel) and model reconstruction in the conjugate hemisphere (right panel) during the ionosphere-plasmasphere storm on 15 December, 2006, at the solar minimum. The solid line indicates the median values, and the dashed line denotes the instant values.

given in Figs. 5 and 6 to demonstrate the improvement. The instantaneous maps of $f_{\mathrm{o}} F_{2}$ are presented for the area under investigation on 16 July, 2000, at the solar maximum, around local noon after the storm onset, and local nighttime at the peak of the storm, respectively. The left panels in Figs. 5 and 6 are based on ionosonde SS observations only. In the right panel, the SS data are complemented with the $\mathrm{CP}$ retrieved critical frequency. The SS locations are shown by circles, and CPs are indicated with diamonds.
The ionospheric plasma density near the equator and its structure are determined by the processes that dictate its production, loss, and transport (see, e.g., Rishbeth (2000)). Production of plasma occurs during daylight hours when the sun illuminates the atmosphere at both conjugate hemispheres while the night-time production is small. For the daytime, with combined SS and CP data, the equatorial anomaly of enhanced peak plasma density at both sides of the magnetic equator in Fig. 5(b) has a stronger symmetry 

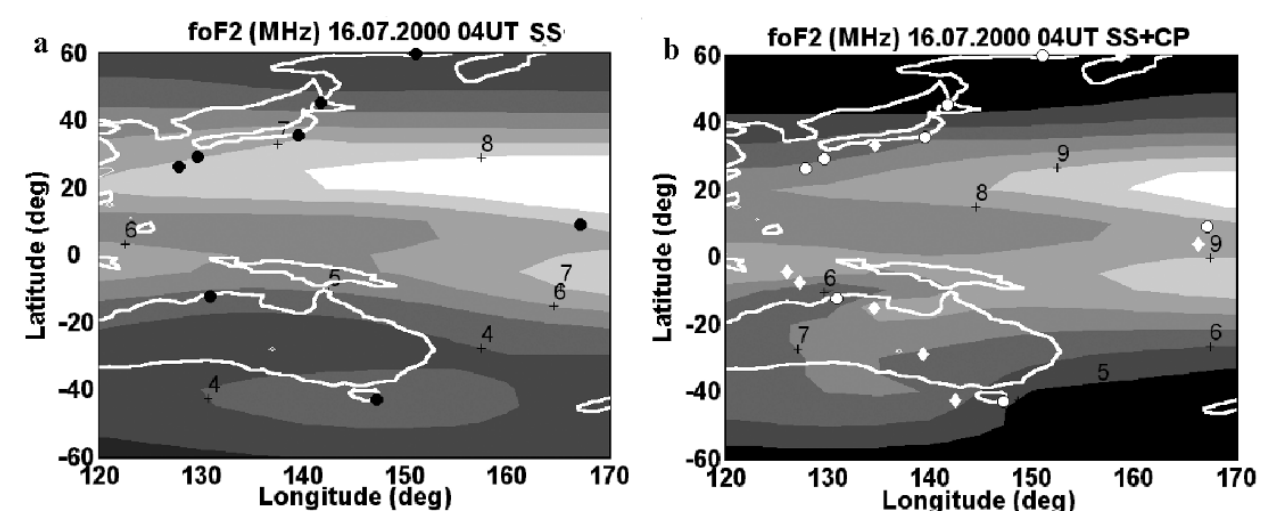

Fig. 5. Maps for the instantaneous $F_{2}$-layer critical frequency during the storm at local daytime hours on 16 July, 2000 , using (a) data of ionosonde observations alone, (b) data of ionosonde observations combined with model estimates at conjugate locations.
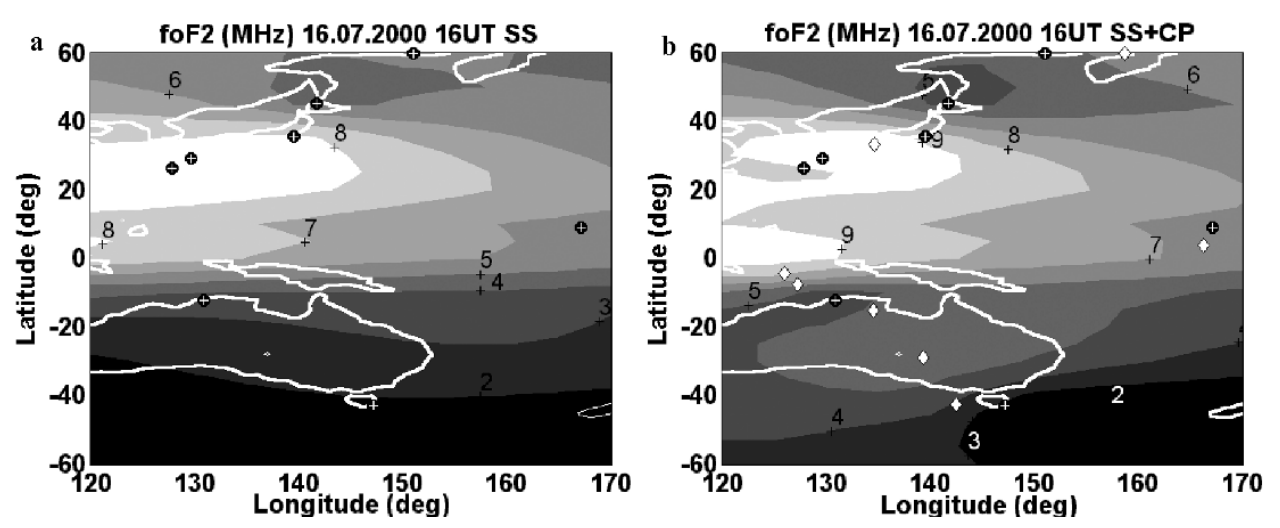

Fig. 6. Maps for the instantaneous $F_{2}$-layer critical frequency during the storm at local night-time hours on 16 July, 2000 , using (a) data of ionosonde observations alone, (b) data of ionosonde observations combined with model estimates at conjugate locations.

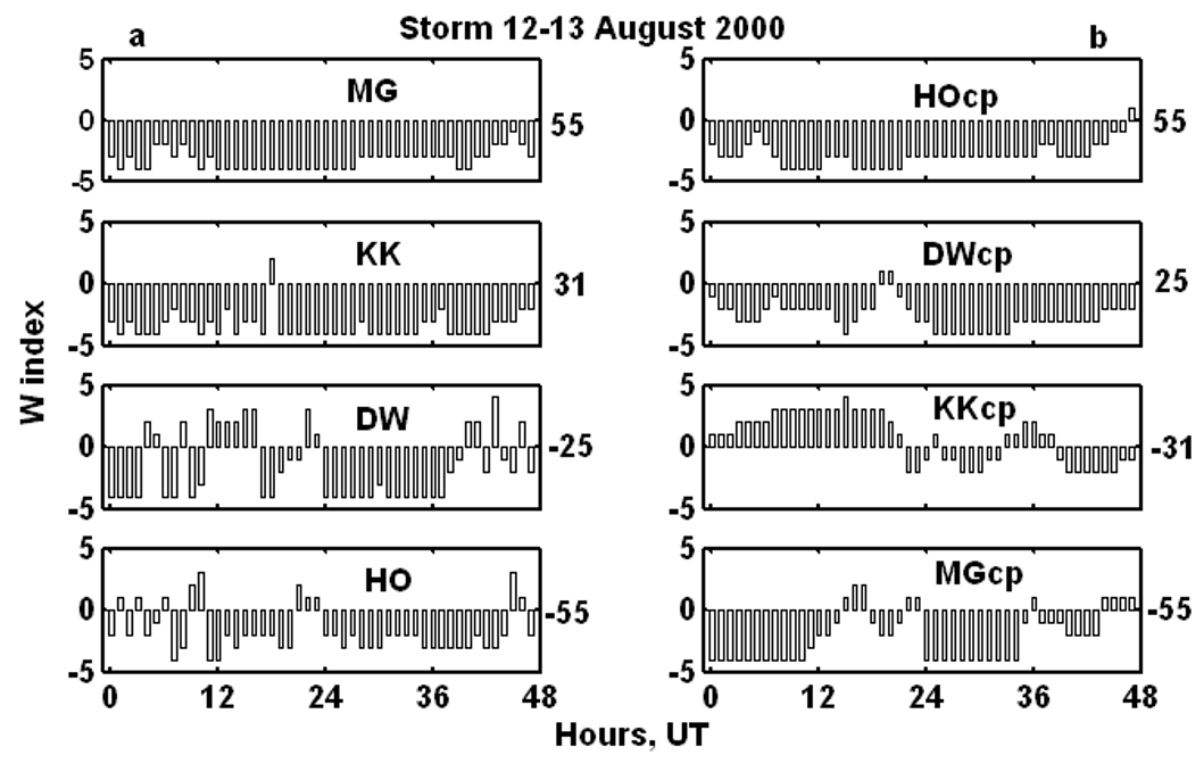

Fig. 7. Ionospheric weather index $W$ at source stations (left panel) and their conjugate counterparts (right panel) during the ionospheric storm at the solar maximum on 12-13 August, 2000 (the event shown in Fig. 3).

compared to that of Fig. 5(a). The night-time electron density distribution in the Northern and Southern hemispheres is asymmetric, which is indicated with the enhanced peak electron density at the Northern summer night and the reduced peak electron density at the Southern summer night map, as rightfully observed with combined SS and CP data in Fig. 6(b). This is a well-known effect of winter anomaly in the peak ionization enhanced (superimposed) by plasma exchange along the field lines during the peak of the space weather storm. 


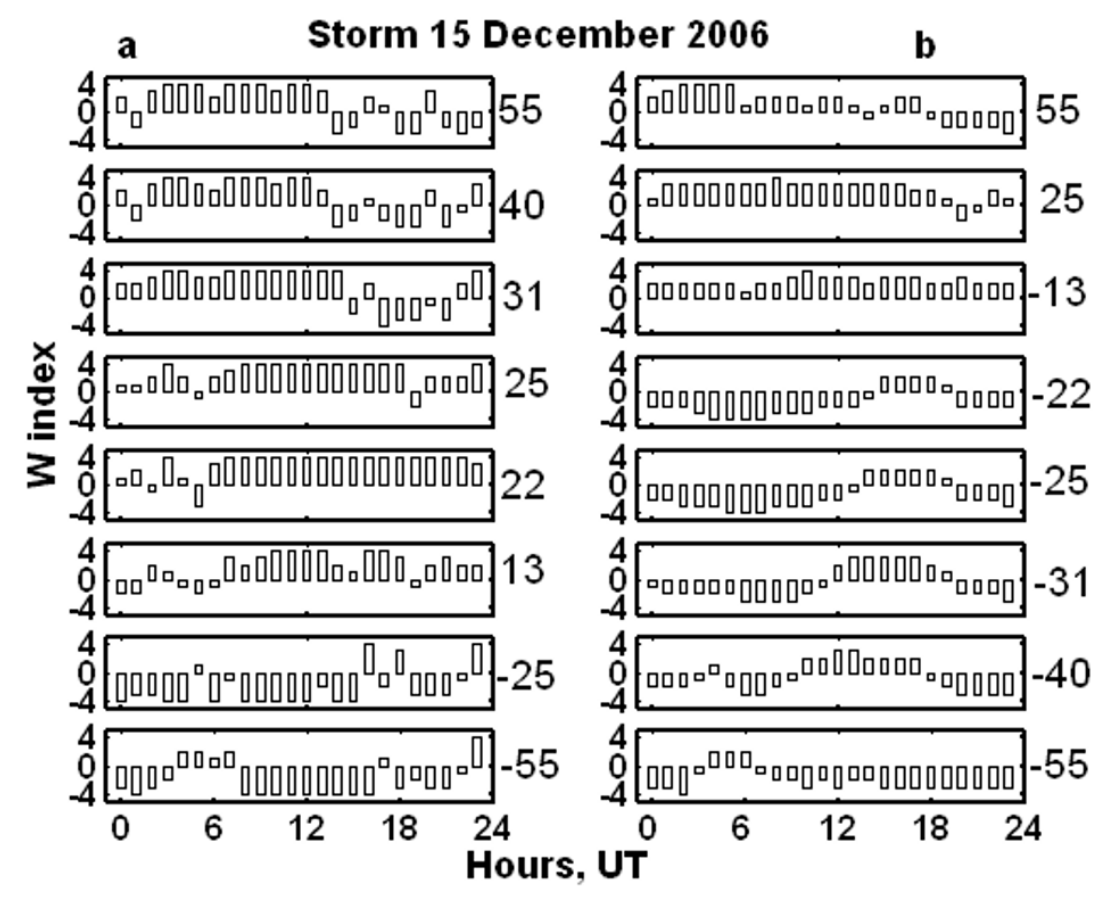

Fig. 8. Ionospheric weather index $W$ at the source stations (left panel) and their conjugate counterparts (right panel) during the ionospheric storm at the solar minimum on 15 December, 2006 (shown in Fig. 4).

The IRI-Plas model output is complemented by the evaluation of the ionospheric weather index, $W$, as a measure of the departure of the instantaneous value of $N_{\mathrm{e}} F_{2}$ from the median. The value of $W$ can vary from \pm 1 representing the quiet state to \pm 4 indicator of the intense storm as discussed in detail in Gulyaeva et al. (2008). In Fig. 7, the computed $W$ values of the ionospheric plasma state during the storm on 12-13 August, 2000 (the event shown in Fig. 3) produced with the SS critical frequency (a) and the retrieved $\mathrm{CP}$ critical frequency (b) are presented. Here, the dominant negative storm effect is captured by four ionosonde stations (two in the Northern hemisphere and two in the Southern hemisphere). The same effect is observed in the results for their counterparts in the opposite hemispheres.

Changes in the $W$ index are also shown in Fig. 8 referring to the storm on 15 December, 2006 (shown in Fig. 4). Again there is evidence of the congruent changes of the SS (a) and the $\mathrm{CP}$ (b) $W$ index in the relevant hemisphere which is indicated by the corrected magnetic latitude at the right border of each panel. The storm time effects are clearly detected by values of the $W$ index equal to \pm 3 and \pm 4 .

\section{Discussion and Conclusions}

The investigation of ionospheric irregularities along the magnetic field line and through magnetic conjugate phenomena has proven to be highly advantageous. Along with the introduction of Earth-based GPS receivers, a costeffective method of producing GIM and the observation of ionospheric irregularities and conjugate phenomena have been made possible since the last solar maximum of 19992001. In this study, a new technique for the reconstruction of the peak electron density and the topside scale height at the conjugate hemisphere is proposed based on recent developments in the International Reference Ionosphere, ex- tended to the plasmasphere, the IRI-Plas code, and the availability of $\mathrm{TEC}_{\mathrm{gps}}$ data through GIM.

Hourly ionosonde observations for eight source stations, SS, in the Northern and Southern hemispheres at the AsiaFar East region are included in the investigation. The performance of the IRI-Plas code is evaluated with the data from ionosonde stations during the storm events listed in Table 2 that occurred in the years of both solar maximum (2000) and solar minimum (2006). It is observed that TEC iri $_{\text {in }}$ is estimated with the higher accuracy if the $F_{2}$-layer peak parameters and $\mathrm{TEC}_{\mathrm{gps}}$ are available to the program at the same time.

An analytical expression to represent the opposite changes of the $F_{2}$-layer critical frequency and the topside scale height is also derived including the term of solar activity retrieved with the IRI-Plas model incorporating $\mathrm{TEC}_{\mathrm{gps}}$. Though there are more relevant solar proxy indices for TEC modeling and decomposition than sunspot numbers (Maruyama, 2010), the sunspot number is used in the present study because it remains the IRI driving parameter, in particular, due to well-established predictions of the 12-months smoothed sunspot numbers a few months in advance.

From Table 3, the RMS error for the median values are significantly less than those for the instantaneous parameter values. This fact may be due to the more smoothed median behavior than the instantaneous storm-time values. The difference in the instant parameters can be explained by different processes governing plasma at the different altitude ranges over the Earth. It is well known that the ionosphere, a conductive, ionized region of the Earth's atmosphere, exhibits significant variations in the peak plasma density residing typically in a relatively thin layer $(200-400 \mathrm{~km})$ in the $F$-region. On the other hand, the storm-time effects 
on $\mathrm{TEC}_{\mathrm{gps}}$ including both the ionosphere and the plasmasphere at altitudes up to a few Earth's radii is controlled by an electric field induced by the Earth's rotation which forces the plasma to co-rotate with the Earth, while, at the higher $L$ shells, the plasma motion is driven by a convection electric field caused by the solar wind interaction with the Earth's magnetosphere. Also, the input parameters of the IRI-Plas code $\left(f_{\mathrm{o}} F_{2}, h_{\mathrm{m}} F_{2}, \mathrm{TEC}_{\mathrm{gps}}\right)$ are not measured directly neither by the ionosonde nor the GPS receiver. These parameters are derived quantities that include modeling, computational and measurement errors due to a sophisticated pre-processing and signal manipulation (Piggot and Rawer, 1972; Arikan et al., 2002, 2007; Reinisch et al., 2005; Smith et al., 2008; Anghel et al., 2009). Therefore, this inherited controversy of input parameters may affect IRI-Plas results and yield greater RMS errors with an instantaneous input than with the more-smoothed monthly median values.

As seen in the examples provided in Figs. 3, 4, 7, and 8, the storm-time effects in the peak electron density of the conjugate hemisphere retrieved with the proposed model anchored to $\mathrm{TEC}_{\mathrm{gps}}$ tend to display a congruent behavior with the ionosonde data in the same hemisphere. At the same time, either symmetry or asymmetry of the peak plasma density variations can occur in SS-CP pairs of data depending on the $F_{2}$-layer storm time dominant signatures at a particular region, season and local time. However, ambiguities in the symmetry or asymmetry of the ionosphere changes in the conjugate hemispheres will likely remain, because processes in the ionosphere are governed not only by plasma interchange along field lines but are also greatly affected by forcing from above and below on local and regional scales.

The proposed analysis method indicates that the IRI-Plas code can yield better estimates of the ionospheric parameters at the conjugate hemispheres along with the input of $\mathrm{TEC}_{\mathrm{gps}}$. This is very important for the investigation of ionospheric variability where ionosonde stations are sparse or lacking.

Acknowledgments. This study is made possible by a joint grant from TUBITAK EEEAG 110E296 and RFBR 11-02-91370-CT_a. The ionosonde data used in the present study are provided by NGDC, NOAA, Boulder, CO, USA; NICT, Tokyo, Japan. The IRI source code is available online from NASA's National Space Science Data Center (http://IRI.gsfc.nasa.gov/). The demo software of the IRI-Plas model is presented at the Internet site of IZMIRAN (http://ftp.izmiran.ru/pub/izmiran/SPIM/). Relevant vertical TEC data for the ionosonde locations are extracted from GPS-derived global ionospheric maps GIMJPL provided by the Jet Propulsion Laboratory online at ftp://cddis.gsfc.nasa.gov/pub/gps/products/ionex/. The planetary ionosphere-plasmasphere storms are provided online at http://www.izmiran.ru/services/iweather/storm/. The authors are grateful to two referees for their useful comments and suggestions for further improvement of the submitted manuscript.

\section{References}

Anghel, A., Ch. Carrano, A. Komjathy, A. Astilean, and T. Letia, Kalman filter-based algorithms for monitoring the ionosphere and plasmasphere with GPS in near-real time, J. Atmos. Sol.-Terr. Phys., 71, 158-174, doi:10.1016/j.jastp.2008.10.006, 2009.

Arikan, F., O. Arıkan, and S. Salous, A new algorithm for high-quality ionogram generation and analysis, Radio Sci., 37(1), 4-1-4-11, 2002.
Arikan, F., O. Arıkan, and C. B. Erol, Regularized estimation of TEC from GPS data for certain midlatitude stations and comparison with the IRI model, Adv. Space Res., 39, 867-874, doi:10.1016/j.asr.2007.01.082, 2007.

Besprozvannaya, A. S., Peculiarities of the regular F2 layers, Geomagn Aeron., 27, 728-734, 1987.

Besprozvannaya, A. S., Empirical modeling of the F2 peak density at $50^{\circ}-70^{\circ}$ invariant latitude using magnetic conjugacy, Adv. Space Res., 11(10), 23-28, 1991.

Besprozvannaya, A. S., Empirical modeling of the polar foF2 in the Northern and Southern hemispheres, Adv. Space Res., 16(1), 27-36, 1995.

Bilitza, D., International Reference Ionosphere 2000, Radio Sci., 36(2), 261-275, 2001.

Bilitza, D., N. M. Sheikh, and R. Eyfrig, A global model for the height of the F2-peak using M3000 values from CCIR, Telecomm. J., 46, 549553, 1979.

Bilitza, D., K. Rawer, L. Bossy, and T. L. Gulyaeva, International Reference Ionosphere-past, present and future, Adv. Space Res., 13(3), 3-23, 1993.

Bust, G. S. and C. N. Mitchell, History, current state, and future directions of ionospheric imaging, Rev. Geophys., 46, RG1003, doi:10.1029/2006RG000212, 2008.

Chasovitin, Yu. K., A. V. Shirochkov, A. S. Besprozvannaya, T. L. Gulyaeva et al., An empirical model for the global distribution of density, temperature and effective collision frequency of electrons in the ionosphere, Adv. Space Res., 7(6), 49-52, 1987.

Gulyaeva, T. L., Proxy for the ionospheric peak plasma density reduced by the solar zenith angle, Earth Planets Space, 61(5), 629-631, 2009.

Gulyaeva, T. L., Storm time behavior of topside scale height inferred from the ionosphere-plasmasphere model driven by the F2 layer peak and GPS-TEC observations, Adv. Space Res., 47, 913-920, doi: 10.1016/j.asr.2010.10.025, 2011.

Gulyaeva, T. L. and I. Stanislawska, Derivation of a planetary ionospheric storm index, Ann. Geophys., 26(9), 2645-2648, 2008.

Gulyaeva, T. L. and I. Stanislawska, Magnetosphere associated storms and autonomous storms in the ionosphere-plasmasphere environment, J. Atmos. Sol.-Terr. Phys., 72, 90-96, doi:10.1016/j.jastp.2009.10.012, 2010

Gulyaeva, T. L. and J. E. Titheridge, Advanced specification of electron density and temperature in the IRI ionosphere-plasmasphere model, Adv. Space Res., 38(11), 2587-2595, doi:10.1016/j.asr.2005.08.045, 2006.

Gulyaeva, T. L., X. Huang, and B. W. Reinisch, Plasmaspheric extension of topside electron density profiles, Adv. Space Res., 29(6), 825-831, 2002

Gulyaeva, T. L., I. Stanislawska, and M. Tomasik, Ionospheric weather: Cloning missed foF2 observations for derivation of variability index, Ann. Geophys., 26(2), 315-321, 2008.

Illes-Almar, E. and I. Almar, A North-South asymmetry in thermospheric density, Adv. Space Res., 38, 2461-2464, doi:10.1016/j.asr.2006.04.031, 2006.

Komjathy, A., R. B. Langley, and D. Bilitza, Ingesting GPS-derived TEC data into the International Reference Ionosphere for single frequency radar altimeter ionospheric delay corrections, Adv. Space Res., 22(6), 793-801, 1998.

Le, H., L. Liu, X. Yue, and W. Wan, The ionospheric behavior in conjugate hemispheres during the 3 October 2005 solar eclipse, Ann. Geophys., 27, 179-184, 2009.

MacDougall, J., M. A. Abdu, and I. Batista, Conjugate Sporadic-E measurements, J. Atmos. Sol.-Terr. Phys., 71, 1333-1339, doi:10.1016/ j.jastp.2009.05.009, 2009.

Manucci, A. J., B. D. Wilson, D. N. Yuan, C. M. Ho, U. J. Lindqwister, and T. F. Runge, A global mapping technique for GPS-derived ionospheric total electron-content measurements, Radio Sci., 33(3), 565-582, 1998.

Maruyama, T., Solar proxies pertaining to empirical ionospheric total electron content models, J. Geophys. Res., 115, A04306, doi:10.1029/ 2009JA014890, 2010.

Matsushita, S., Ionospheric F2 behavior at conjugate places in low latitudes, Radio Sci., 3(7), 658-667, 1968.

McNamara, L. F., J. M. Retterer, M. A. Abdu, I. S. Batista, and B. W. Reinisch, F2 Peak parameters, drifts and spread F derived from digisonde ionograms for the COPEX campaign in Brazil, J. Atmos. Sol.Terr. Phys., 70(8), 1144-1158, 2008.

Nayir, H., F. Arikan, O. Arikan, and C. B. Erol, Total Electron Content Estimation with Reg-Est, J. Geophys. Res.-Space Phys., 112, A11313, doi:10.1029/2007JA012459, 2007. 
Ostgaard, N., S. B. Mende, H. U. Frey, J. B. Sigwarth, A. Asnes, and J. M. Weygand, Auroral conjugacy studies based on global imaging, J. Atmos. Sol.-Terr. Phys., 69(3), 249-255, doi:10.1016/j.jastp.2006.05.026, 2007. Piggott, W. R. and K. Rawer, URSI Handbook of ionogram interpretation and reduction, Second ed., Upper Atmospheric Geophysics, Report $U A G-23 A$, NGDC/NOAA, November 1972.

Rawer, K., Synthesis of ionospheric electron density profiles with Epstein functions, Adv. Space Res., 8(4), 191-199, 1988.

Rawer, K., Proposed improvement of the IRI topside profile formula, $A d v$. Space Res., 10(11), 75-78, 1990.

Reinisch, B. W., X. Huang, I. A. Galkin, V. Paznukhov, and A. Kozlov, Recent advances in real-time analysis of ionograms and ionospheric drift measurements with digisondes, J. Atmos. Sol.-Terr. Phys., 67(12), 1054-1062, 2005.

Rishbeth, H., The equatorial F-layer: progress and puzzles, Ann. Geophys., 18, 730-739, 2000.

Rotwell, P., Charged particles in the Earth's magnetic field and the ionospheric F2-layer, J. Phys. Soc. Jpn., 17, Suppl. 1, 263-267, 1962.

Shiokawa, K., Y. Otsuka, T. Tsugawa, T. Ogawa, A. Saito, K. Ohshima, M. Kubota, T. Maruyama, T. Nakamura, M. Yamamoto, and P. Wilkinson, Geomagnetic conjugate observation of nighttime medium-scale and large-scale traveling ionospheric disturbances: FRONT3 campaign, J. Geophys. Res., 110, A05303, doi:10.1029/2004JS010845, 2005.
Smith, D. A., E. A. Araujo-Pradere, C. Minter, and T. Fuller-Rowell, A comprehensive evaluation of the errors inherent in the use of a twodimensional shell for modeling the ionosphere, Radio Sci., 43, RS6008, doi:10.1029/2007RS003769, 2008.

Stankov, S. M., N. Jakowski, S. Heise, P. Muhtarov, I. Kutiev, and R. Warnant, A new method for reconstruction of the vertical electron density distribution in the upper ionosphere and plasmasphere, J. Geophys. Res., 108(A5), 1164, doi:10.1029/2002JA009570, 2003.

Uemoto, J., T. Ono, T. Maruyama, S. Saito, M. Iizima, and A. Kumamoto, Magnetic conjugate observation of the $F_{3}$ layer using the SEALION ionosonde network, Geophys. Res. Lett., 34, L02110, doi:10.1029/2006GL028783, 2007.

Watanabe, M., A. Kadokura, N. Sato, and T. Saemundsson, Absence of geomagnetic conjugacy in pulsating auroras, Geophys. Res. Lett., 34(15), L15107, doi:10.1029/2006GL030469, 2007.

Yizengaw, E., P. L. Dyson, and E. A. Essex, A study of the spatial distribution in the topside ionosphere and plasmasphere using FedSat GPS receiver, Adv. Space Res., 38, 2318-2323, 2006.

T. L. Gulyaeva (e-mail: gulyaeva@izmiran.ru), F. Arikan, and I. Stanislawska 